\title{
Design and testing of a heat transfer sensor for well exploration tools
}

\author{
Soprani, Stefano; Just Nørgaard, Anders; Nesgaard, Carsten ; Engelbrecht, Kurt
}

Published in:

Applied Thermal Engineering

Link to article, DOI:

10.1016/j.applthermaleng.2018.06.034

Publication date:

2018

Document Version

Peer reviewed version

Link back to DTU Orbit

Citation (APA):

Soprani, S., Just Nørgaard, A., Nesgaard, C., \& Engelbrecht, K. (2018). Design and testing of a heat transfer sensor for well exploration tools. Applied Thermal Engineering, 141, 887-897.

https://doi.org/10.1016/j.applthermaleng.2018.06.034

\section{General rights}

Copyright and moral rights for the publications made accessible in the public portal are retained by the authors and/or other copyright owners and it is a condition of accessing publications that users recognise and abide by the legal requirements associated with these rights.

- Users may download and print one copy of any publication from the public portal for the purpose of private study or research.

- You may not further distribute the material or use it for any profit-making activity or commercial gain

- You may freely distribute the URL identifying the publication in the public portal

If you believe that this document breaches copyright please contact us providing details, and we will remove access to the work immediately and investigate your claim. 


\title{
Design and Testing of a Heat Transfer Sensor for Well Exploration Tools
}

\author{
Stefano Soprani*a ${ }^{*}$, Anders Just Nørgaard ${ }^{\mathrm{b}}$, Carsten Nesgaard ${ }^{\mathrm{c}}$, Kurt Engelbrecht ${ }^{\mathrm{a}}$ \\ ${ }^{a}$ Department of Energy Conversion and Storage, Technical University of Denmark, Frederiksborgvej 399, \\ 4000 Roskilde, Denmark. \\ ${ }^{\mathrm{b}}$ Just Consulting IVS, Frederiksdalsvej 5 B, 2830 Virum, Denmark. \\ ${ }^{c}$ Development \& Engineering, Welltec, Inc., 22440 Merchants Way, Katy, Texas 77449, USA.
}

\begin{abstract}
The exploration of oil, gas, and geothermal wells is moving towards increasingly harsher downhole environments, requiring more and more advanced drilling and intervention tools. The high downhole temperatures threaten the correct functionality of intervention equipment and of standard downhole electronics, which cannot withstand temperatures above $150{ }^{\circ} \mathrm{C}$ for an extended period of time. Thermal management of downhole electronics therefore requires critical and accurate knowledge of the thermal interaction between the downhole tools and the wellbore environment for correct tool design, intervention planning and operation. In this work, we present the design, modelling and testing of a sensor for downhole tools that can determine the heat transfer rate between the tool and the harsh downhole environment. An experimental flow loop was used to simulate the interaction between the sensor and the well fluid, and to calibrate the sensor in the range of heat transfer coefficients $0-1000 \mathrm{~W} / \mathrm{m}^{2} \mathrm{~K}$. Good agreement between model predictions and experimental results was obtained with average and maximum errors of $\sim 3 \%$ and $\sim 10 \%$, respectively. A sensitivity of up to $8.7 \mathrm{mV} /\left(\mathrm{W} / \mathrm{m}^{2} \mathrm{~K}\right)$ was measured and a response time of about 11 seconds was obtained over a $25 \%$ change in the fluid velocity.
\end{abstract}

Keywords: downhole electronics, well interventions, downhole sensor, convective heat transfer, thermally developing flow.

\section{Introduction}

High temperature (HT) wells represent a significant challenge for drilling and exploration operations in the oil, gas, and geothermal industries [1]. Standard downhole electronics employed in well intervention tools cannot withstand the HT well temperatures $\left(>150^{\circ} \mathrm{C}\right)$ for an extended period of time, increasing the chances of overheating and intervention tool failure [2]. Thermal management of downhole electronics has therefore become an extremely relevant and strategic topic within the design and operation of downhole tools. Several approaches have been investigated to maintain the electronics to tolerable temperatures, ranging from passive cooling solutions [3-5] to active cooling systems [6-12]. 
Effective design and implementation of thermal management strategies strongly rely on the knowledge of the thermal interaction between the downhole electronics and the surrounding downhole environment, which characterizes the heating rate and operating temperature of the electronic components. Accurate calculation of each thermal resistance involved in the system is fundamental for such design process and can improve the risk management related to electronics overheating failures. The thermal resistances defined by the installation of the electronics in the tool, which often relies on a metallic cartridge and pressure-resistant housing as show in Figure 1, can be opportunely dimensioned according to the thermal management strategy. Nevertheless, the thermal interaction between the tool housing and the wellbore, characterized by $R_{t h \text { ho-well }}$, is often unknown and very difficult to predict, as it depends on a large number of assumptions and input data $[7,8,11]$.

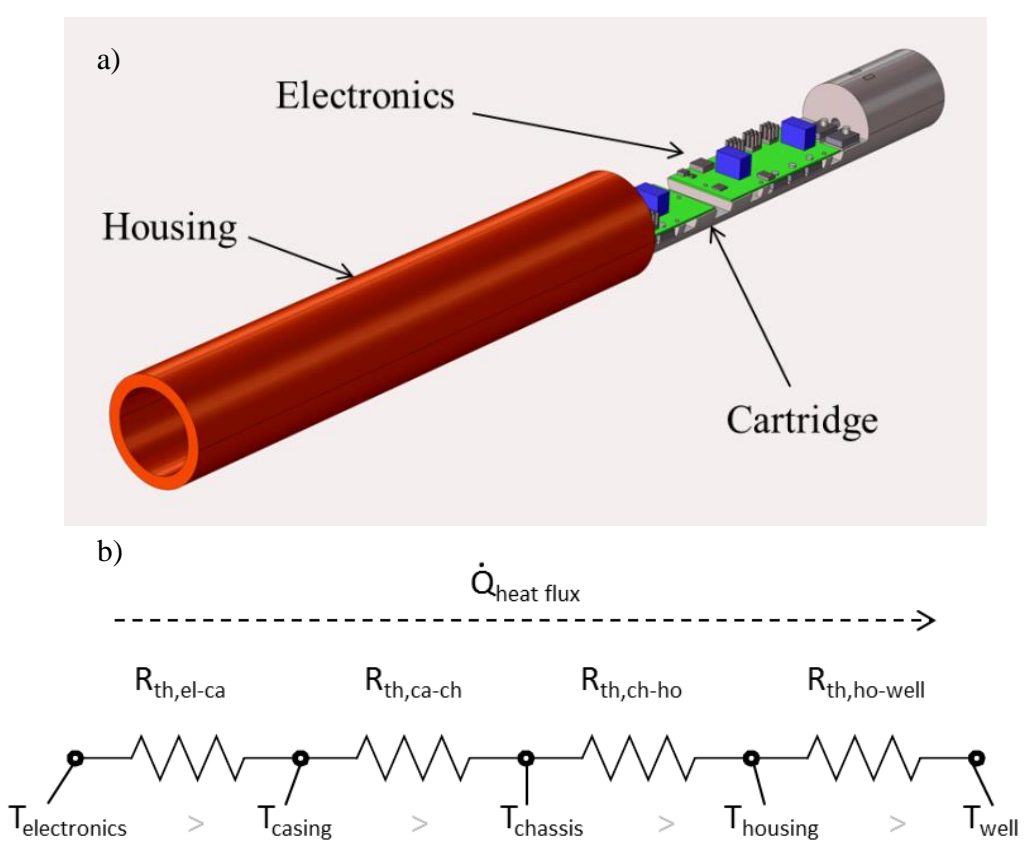

Figure 1. 3D reconstruction of a downhole electronics tool section (a) and 1D schematic representation of the thermal resistances involved in a passive cooling system (b). $R_{t h, e l-c a}$ represents the thermal resistance between the semiconductor substrate and the electronics casing, $R_{t h, c a-c h}$ reresents the thermal resistance between the electronics casing and the cartridge, $R_{t h, c h-h o}$ represents the thermal resistance between the cartridge and the housing, and $R_{\text {th,ho-well }}$ represents the thermal resistance between the housing and the well. $\dot{Q}_{\text {heat,flux }}$ represents the heat flux exchanged between the electronics and the wellbore, and can flow in either direction depending wether the electronics is above or below the well temperature.

The thermal resistance between the tool and the wellbore can be quantified through the overall heat transfer coefficient $U_{\text {ho-well }}$, which describes the amount of heat exchanged between the tool and the well, per unit of housing outer area $\left(A_{\text {housing }}\right)$, and per degree of temperature difference. $U_{\text {ho-well }}$ accounts for heat conduction, convection and radiation.

$R_{\text {th,ho-well }}=\frac{1}{U_{\text {ho-well }} A_{\text {housing }}}$

Only a few works reported in literature have analyzed the thermal interaction between a downhole tool and the downhole environment. Flores [7] studied the thermal interaction between a moving exploration tool and the well fluid in the case of plug, laminar and Bingham-Plastic flow. Convection was considered as the 
dominant heat transfer mechanism, while conduction and radiation were neglected. A minimum heat transfer coefficient of $100 \mathrm{~W} / \mathrm{m}^{2} \mathrm{~K}$ was estimated for a mixture of water, oil and clay, and set as design boundary condition for the design of an active cooling system. The scenario of a stationary tool, which neglected free convection and assumed zero fluid velocity, was also presented and a heat transfer coefficient of $7 \mathrm{~W} / \mathrm{m}^{2} \mathrm{~K}$ was calculated. The heat transfer coefficient between downhole tools and downhole environments was also briefly discussed in [8]. The performance of an actively cooled prototype of downhole electronics was tested in air, with an estimated heat transfer coefficient of $50 \mathrm{~W} / \mathrm{m}^{2} \mathrm{~K}$. It was reported, however, that the heat transfer rate in the wellbore was expected to be much higher than the one experienced in the laboratory tests. In [11] a sensitivity study is presented to show how the performance of downhole active cooling systems relies on the heat rejection rate to the wellbore and how low heat transfer rates $\left(10-1000 \mathrm{~W} / \mathrm{m}^{2} \mathrm{~K}\right)$ can be critical for thermal management strategies. Studies on convective heat transfer during drilling operations were performed by [13-15] and correlations to estimate the Nusselt number in the case of laminar and turbulent flow in a drill pipe, annulus and at the drill bit were also provided. Other studies analyzed and modelled the heat transfer within wellbores, mainly focusing on the interaction of the well fluid with the well casing and formation [16-21]. These models are however limited to specific operating conditions (e.g. drilling, cementing, steam injection) and require an enormous amount of inputs (well shape and dimensions, fluid composition, fluid thermal properties) that are often unknown to those who provide the well intervention service.

The integration of a heat transfer sensor would allow measuring experimentally the heat transfer between the tool and the wellbore, without relying on any fluid or borehole properties. Different designs of heat transfer gauges are discussed in [22]. Sensors can measure heat transfer by measuring a temperature gradient in space, such as for planar [23] and thin foil sensors [24]; by measuring a temperature gradient in time and evaluating a time constant [25]; or by actively dissipating a controlled amount of heat. An extensive review of heat transfer sensors based on the thin foil technology is also reported in [26], with an overview on thinfilm heat flux sensors, which given the reduced thickness have a lower thermal disruption effect. Thermal studies in high-temperature [27] and high-pressure environments, such as die casting molds [28] or gas turbines [29, 30], show how heat transfer measurements require the development of new materials, additional shielding of sensors, and even the integration of active cooling systems, which increase the complexity and the cost of the sensor. One major drawback of all these sensors for this application is robustness and temperature resistance. None of the previously mentioned sensors can be implemented using existing designs in the downhole application due to mechanical/chemical limitations, because the temperature range is too high or because they require complex electronics.

In this work we propose the design of a low-complexity, inexpensive and robust heat transfer sensor, which is optimized for integration in downhole tools, relies on the use of high temperature electronics, and is able to operate in harsh and chemically aggressive environments. The data measured by the downhole sensor could be used:

- "In real-time": coupled with an active cooling system, the sensor could adjust the cooling system operating condition to the optimal one, based on wellbore conditions [11]. Additionally, the sensor could be employed to detect anomalous downhole events such as infiltrations, clogging, or increased presence of bubbles, which can cause sudden changes in the heat transfer conditions.

- "Post-acquisition": a database could be built by measuring the downhole heat transfer coefficient for different wells, fluids, depths and well intervention types. Such a database could be used both for the thermal 
design of new tools, to predict the electronics temperatures during the intervention-planning phase, and to mitigate the risk of electronics overheating.

The working principle, modelling, experimental testing and calibration of the sensor are presented for a laboratory scale setup. Accuracy and sensitivity of the sensor are analyzed and compared for different operating conditions.

\section{Background}

Defining a simplified study case can be useful to picture the type of thermal interaction that needs to be monitored and to elaborate the heat transfer design of the sensor. Heat convection can be considered the dominant downhole heat transfer mechanism, compared to conduction and radiation [7]. Thus, it can be said that the heat transfer between the tool and the well fluid is driven by the well fluid lapping the outer surface of the tool and developing a temperature and velocity profile, as qualitatively illustrated in Figure 2 . The heat transfer coefficient $U_{\text {ho-well }}$ can be therefore approximated with good accuracy with the convective heat transfer coefficient $h$.

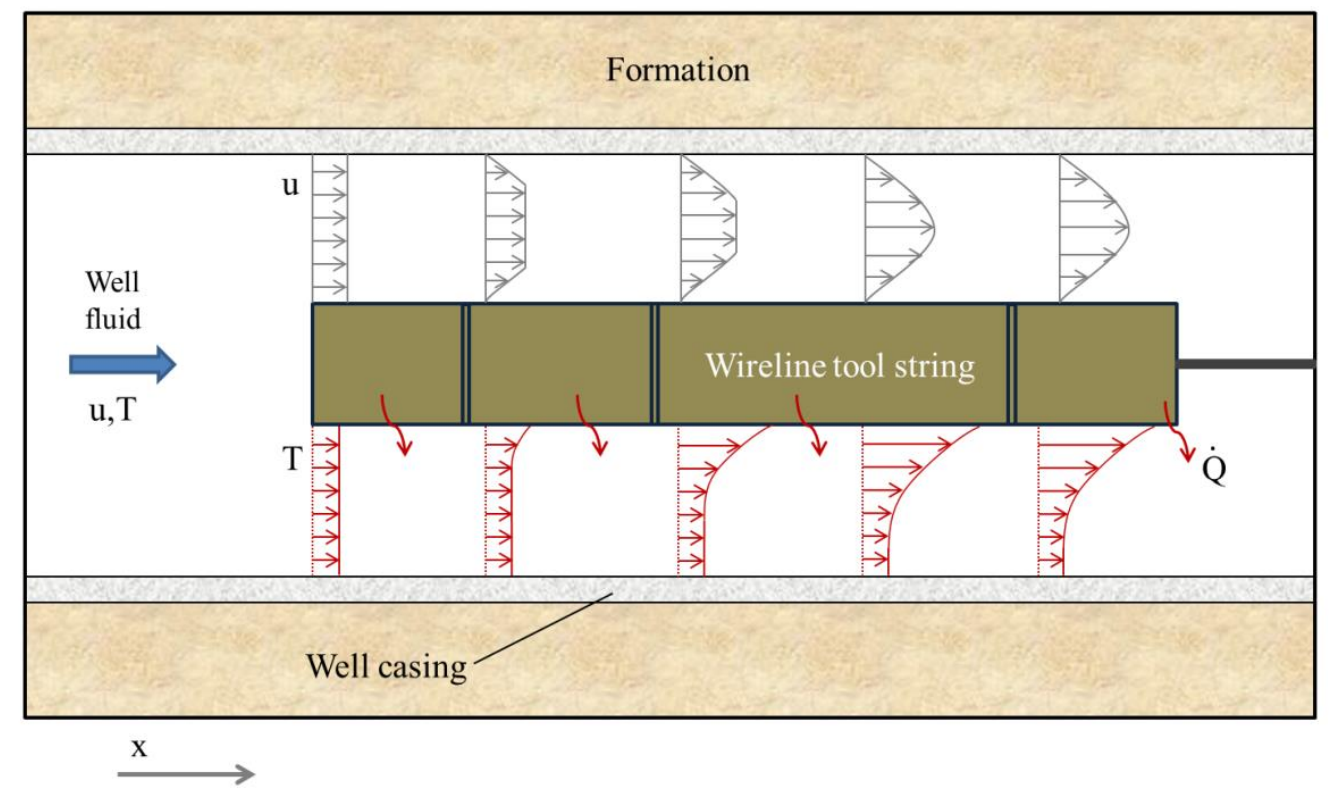

Figure 2 Schematic of the idealized interaction between a downhole tool string and the well fluid flow, with velocity $u$ and temperature $T$. The qualitative development of the velocity and temperature profiles is illustrated, with the assumption that the tool string dissipates a uniform heat flux $\dot{Q}$ and the well fluid is single-phase. The illustrated velocity profile resumes more of a laminar flow parabolic distribution. In the case of turbulent flow, the $u$ profile is described by a flatter curve that still evolves towards a hydro-dynamically developed state.

Assuming that the wireline tool has a cylindrical shape, a constant cross section, and is centered in the middle of the wellbore, the type of flow can be approximated as (i) annular. The flow can be further classified as (ii) hydro-dynamically and thermally (simultaneously) developing, if we assume that annular velocity and temperature profiles start to develop when the well fluid first interacts with the downhole tool. Depending on the fluid's Reynolds number, the flow could be (iii) laminar, transitional, or turbulent. A further simplification could be to assume that the well fluid is (iv) single phase (oil, gas, or water) and 
exchanges heat with the downhole tool at a (v) constant heat flux. Correlations that express the Nusselt number for this ideal case can be found in literature [31]. The Nusselt number is defined as a function of the position along the tool $x$, the Peclet number $P e$, and the ratio between the well casing and tool diameters. The Nusselt number tends to assume an asymptotic value as the flow becomes fully developed.

However, the thermal interaction between the tool string and the well environment in a non-ideal scenario is significantly different from the case represented in Figure 2. The tool orientation and position in the wellbore continuously change and the well fluid can be composed of several phases. The diameter of the tool string can vary and additional geometric features (e.g. fins or sensors) can disrupt the development of the velocity profile. Furthermore, the power dissipation along the tool is not uniform and different tool sections can influence the temperature profile of the well fluid in different ways. It is therefore very complex to forecast the heat transfer coefficient between tool and well environment. The great advantage of having a sensor that experimentally measures such a quantity is that none of the aforementioned information about the flow or fluid thermal properties is needed. Given the variability of the heat transfer coefficient along the tool string profile, more than one sensor could be installed to locally measure the downhole heat transfer coefficient and reconstruct its trend along the tool string length or radially at a given location along the tool.

\section{Design of the sensor}

The average convective heat transfer coefficient $h$ over a certain surface can be expressed according to its general definition [23,31] reported in Eq. (2).

$h=\frac{\dot{Q}}{A \cdot\left(T_{\text {surf }}-T_{\text {ext }}\right)}$

Where $\dot{Q}$ is the heat flux rejected through the surface with area $A$ exposed to the lapping fluid, $T_{\text {surf }}$ is the average temperature of the surface, and $T_{e x t}$ is the well fluid bulk mean temperature. The heat transfer coefficient $h$ can be experimentally obtained by measuring the temperature difference between the surface and the lapping fluid when dissipating a certain amount of heat $\dot{Q}$ through a surface area $A$. A downhole sensor should therefore have a surface area $A$ in contact with the well fluid, through which a controlled amount of power $\dot{Q}$ is dissipated. The sensor should also be able to measure both the temperature of the surface and of the well fluid.

This configuration could be achieved by mounting a heat dissipating element into a metallic casing, which is then installed on a downhole tool and put in contact with the well fluid. The dissipating element, fed by a controlled power source, would dissipate heat through the surface of the casing and a temperature sensor would measure the heat rejection temperature. The casing that interfaces the dissipating element to the well should be designed with highly conductive material, so the inner surface temperature can be approximated to the outer one and the thermal gradient across it assumed negligible $(B i \ll 1)$. The well fluid bulk temperature could be measured, instead, by a shielded temperature sensor or by other diagnostic tools already used in the well intervention industry. The control and data acquisition systems could be integrated in the inner part of the tool.

A preliminary analysis of the system led to the following design criteria: 
- The sensor must not interfere, either thermally or electrically, with any other device in the downhole tool. The power dissipated through the sensor should therefore not affect the operating temperature of the other components.

- The sensor must not disrupt the hydro-dynamic development of the flow (fit the outer profile of the tool) and affect the fluid temperature distribution the least possible (not too high power dissipation rates).

- The design must minimize the heat losses to the surrounding to have accurate estimation of the heat transfer coefficient and not to affect the temperature of other components.

- The design must minimize the temperature gradient between the surface exposed to the well fluid and the heat source.

- The design must minimize the response time to measure $h$ and detect possible anomalies in real time. This implies minimizing the sensor thermal mass and heat dissipation surface area.

Furthermore, two operating approaches for the sensor were individuated:

1) Dissipate a fixed heat flux: calculate the heat transfer coefficient by measuring the variable temperature difference between the well fluid and the sensor, given a fixed dissipated heat flux.

2) Set a $\Delta T_{\text {SetPoint }}$ : calculate the heat transfer coefficient by regulating the dissipated heat flux so the temperature difference between well fluid and sensor is maintained at $\Delta T_{\text {SetPoint }}$.

The implementation of approach (1) appears to be less complex and does not require any automated control of the power dissipation. Nevertheless, high power dissipation rates are needed to maintain a significant temperature difference and a good resolution of the measurements at high convection regimes. At the same time, a high heating rate can generate high sensor temperatures during periods of poor convection, which can damage the sensor and the neighboring components. Approach (2), instead, regulates the dissipation rate to maintain a set temperature difference $\left(T_{\text {surf }}-T_{\text {ext }}\right)$ in a range where the temperature sensors give reliable and precise readings. It therefore requires an overall lower dissipation rate. Maintaining a constant temperature difference between the sensor and the well also decreases significantly the response time because the thermal mass of the sensor is maintained at constant temperature and is subject to much shorter temperature transients than for Approach (1).

The analysis of the system led to the sensor design illustrated in Figure 3. 


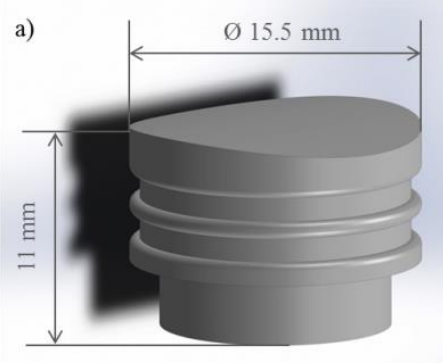

Heat exchange area $=189.5 \mathrm{~mm}^{2}$

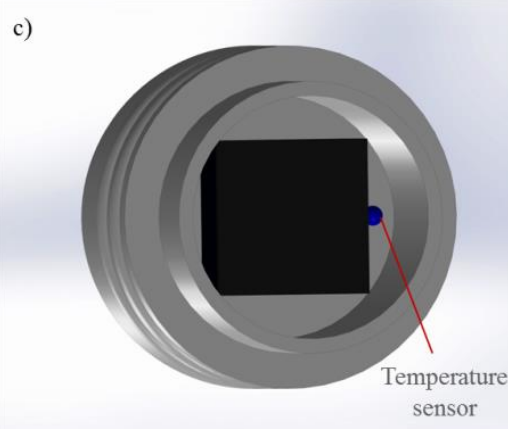

b)

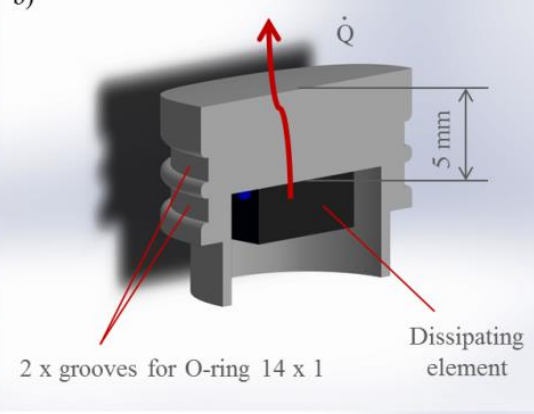

d)

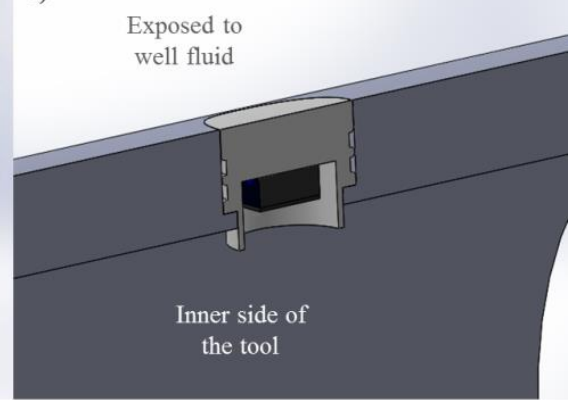

Figure 3 3D CAD model of the sensor casing with dissipating element (a, b, and c) and section-view of the sensor integrated in a downhole tool (d).

The sensor is composed of a hollow metallic casing which houses the dissipating element and the temperature sensor. The dissipating element is mounted on a $5 \mathrm{~mm}$ thick surface that conducts the rejected heat towards the well fluid. When the sensor is assembled in the downhole tool, two o-rings seal the inner side from fluid invasion. The inner part of the tool could host the feeding and data acquisition systems (DAQ). In order to test the concept and the design of the sensor, an experimental setup was designed with room temperature components. The goal of the experimental setup was to reproduce a known flow, for which the convection coefficient could be both measured by the sensor and predicted with correlations from the literature. The comparison between experiments and predictions could also help defining a calibration procedure. The design of the experimental flow loop is presented in the next section.

\section{Experimental setup}

The design of the flow loop is aimed at reproducing known convective heat transfer conditions that could be measured by the sensor and compared with the predictions from the literature. A fluid flow in a circular pipe was chosen for this purpose, given the large availability of heat transfer correlations [31]. In order to interface the sensor with the flow in the circular geometry, its design was slightly modified, as shown in Figure 4. Since the sensor was intended to detect poor heat rejection conditions, a low range of convection coefficients, between 0 and $1000 \mathrm{~W} / \mathrm{m}^{2} \mathrm{~K}$, was reproduced with a laminar flow. 


\subsection{Modeling}

A tube with a circular cross section was chosen as the reference geometry and a solution of water-glycol $10 \%$ vol as heat transfer fluid. The setup aimed at reproducing a hydraulically fully developed and thermally developing flow. A straight tube section needed to be installed before the sensor to let the flow develop hydro-dynamically before encountering the sensor. The flow would then start developing thermally when lapping the small sensor face. The geometry of the sensor was designed to match the profile of the inner diameter of the tube (Figure 4), in order to minimize hydraulic disruption of the flow. A plate was designed at the bottom of the casing to mount the sensor in the setup using four screws.

The software Engineering Equation Solver (EES) [32] was used to build a model of the system and to retrieve the thermo-physical properties of the heat transfer fluid. The model was initially used to perform a parametric study and to find suitable dimensions for the pipe, which could reproduce the desired range of convection coefficients. Eq. (3) and (4), from [31], defined the local and average Nusselt number for thermally developing flow as a function of the axial position and of the flow properties. Eq. (4) was used to calculate the average Nusselt number over the sensor interface, as the integral average of the local Nusselt values. The experimental correlations were both provided for constant temperature boundary condition, in analogy with the experimental conditions.

$$
\begin{aligned}
& N u_{x, T}=\left\{\begin{array}{lr}
1.077 \cdot x^{*-\frac{1}{3}}-0.7 & \text { for } x^{*} \leq 0.01 \\
3.657+6.874 \cdot\left(10^{3} \cdot x^{*}\right)^{-0.488} e^{-57.2 \cdot x^{*}} & \text { for } x^{*}>0.01
\end{array}\right. \\
& N u_{m, T}=\left\{\begin{array}{lr}
1.615 \cdot x^{*-\frac{1}{3}}-0.7 & \text { for } x^{*} \leq 0.005 \\
1.615 \cdot x^{*-\frac{1}{3}}-0.2 & \text { for } 0.005<x^{*}<0.03 \\
3.657+\left(0.0499 / x^{*}\right) & \text { for } x^{*} \geq 0.03
\end{array}\right.
\end{aligned}
$$

Where $N u_{x, T}$ and $N u_{m, T}$ are respectively the local and mean Nusselt numbers, calculated for the constant temperature boundary condition (T). $x *$ is the dimensionless axial coordinate for the thermal entrance region and is defined in Eq. (5). 
a)

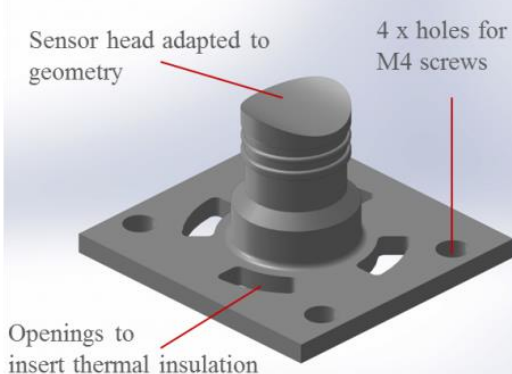

c)

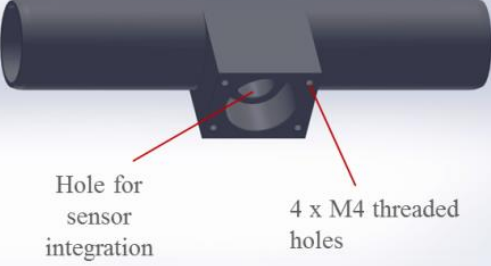

b)

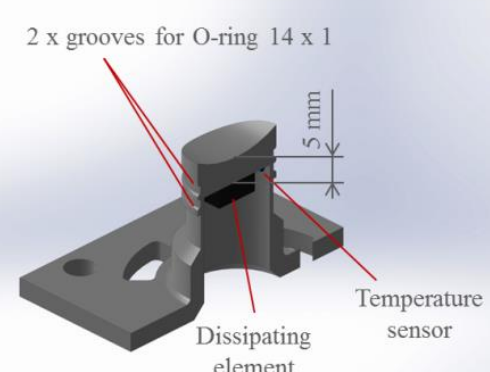

Heat exchange area $=219 \mathrm{~mm}^{2}$

d)

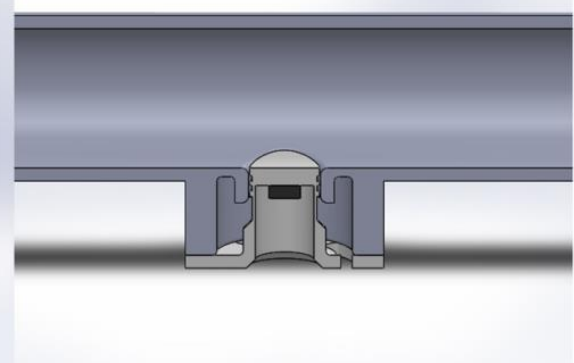

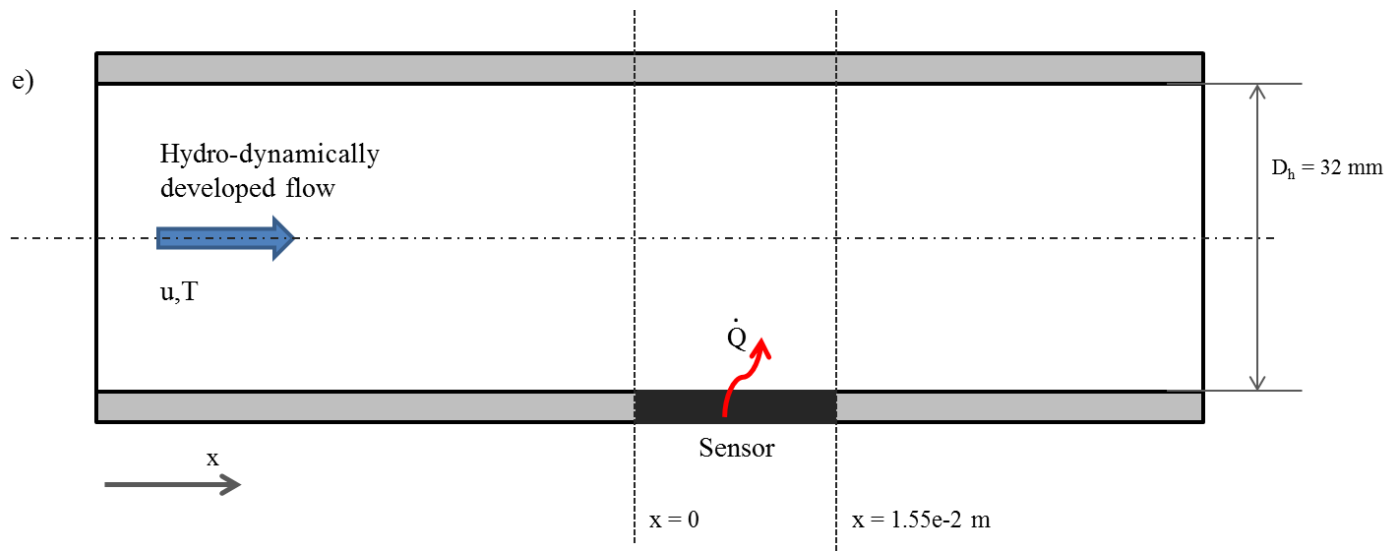

f)

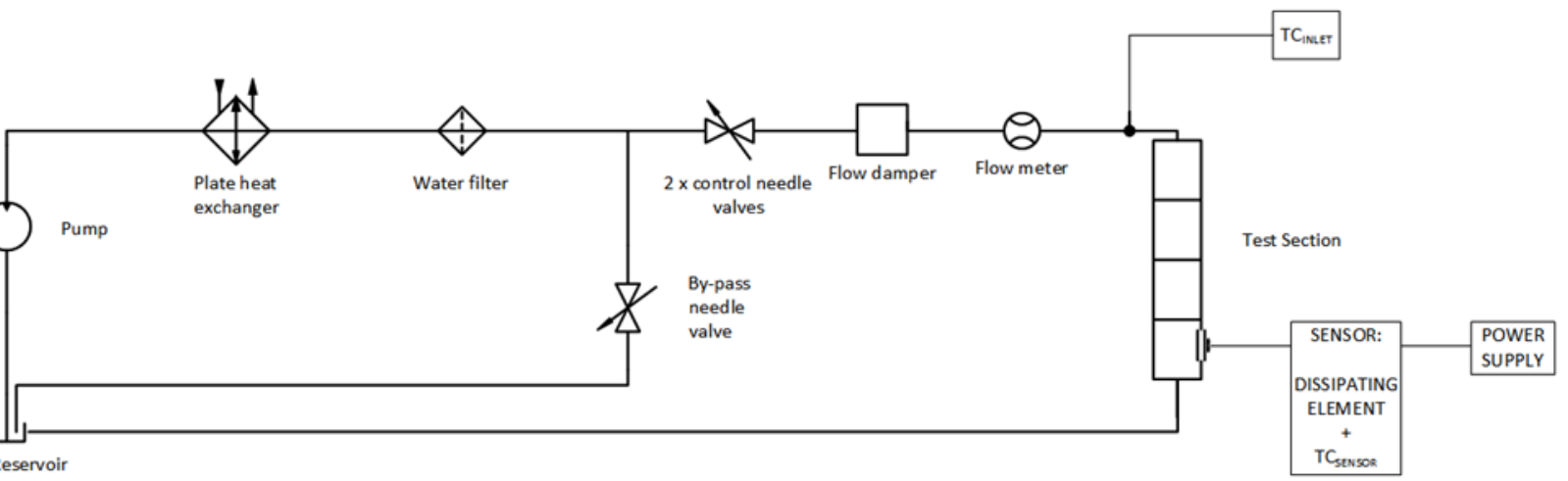

Figure 4 3D CAD model of the sensor modified for integration in the experimental setup. Modified sensor casing with dissipating element ( $a$ and b), pipe section housing the sensor (c), and section-view of the sensor integrated in the pipe section (d). Schematic representation of the thermally developing flow in the sensor section (e). Schematic of the flow loop used for the experimental measurements on the heat transfer coefficient sensor (f). 
$x^{*}=\frac{x}{D_{h} \cdot P e}$

Where $x$ is the axial coordinate along the pipe at which $N u$ is calculated, $D_{h}$ is the hydraulic diameter corresponding to the inner diameter of the pipe, and $P e$ is the Peclet number, defined as the product of the Reynolds and Prandtl numbers. In order to calculate the straight entrance length required for hydraulically developed flow, Eq. (6) from [33] was used:

$L_{\text {entrance }}=0.056 \cdot R e \cdot D_{h}$

for $R e \leq 2300$

The fluid flow rate was calculated as:

$V_{f}=u \cdot \frac{\pi D_{h}^{2}}{4}$

Considering the target operational range of heat transfer coefficients $0-1000 \mathrm{~W} / \mathrm{m}^{2-} \mathrm{K}$ a laminar flow regime is preferable for reproduction of the desired conditions using a water-glycol solution. However, the entrance length decreases with the pipe diameter according to Eq. (6), as well as the required heat transfer fluid flow rate. A tradeoff between pipe dimensions, measurable $h$ range, and required volume flow rates was reached by choosing a diameter of $32 \mathrm{~mm}$. A maximum entrance length of $\sim 4 \mathrm{~m}$ for $R e=2300$ was obtained. The use of a flow straightener could reduce this length in the practical implementation of the setup. The predicted trend of the calculated variables is shown in Figure 5 and represented the reference predictions to compare with the data measured by the sensor.

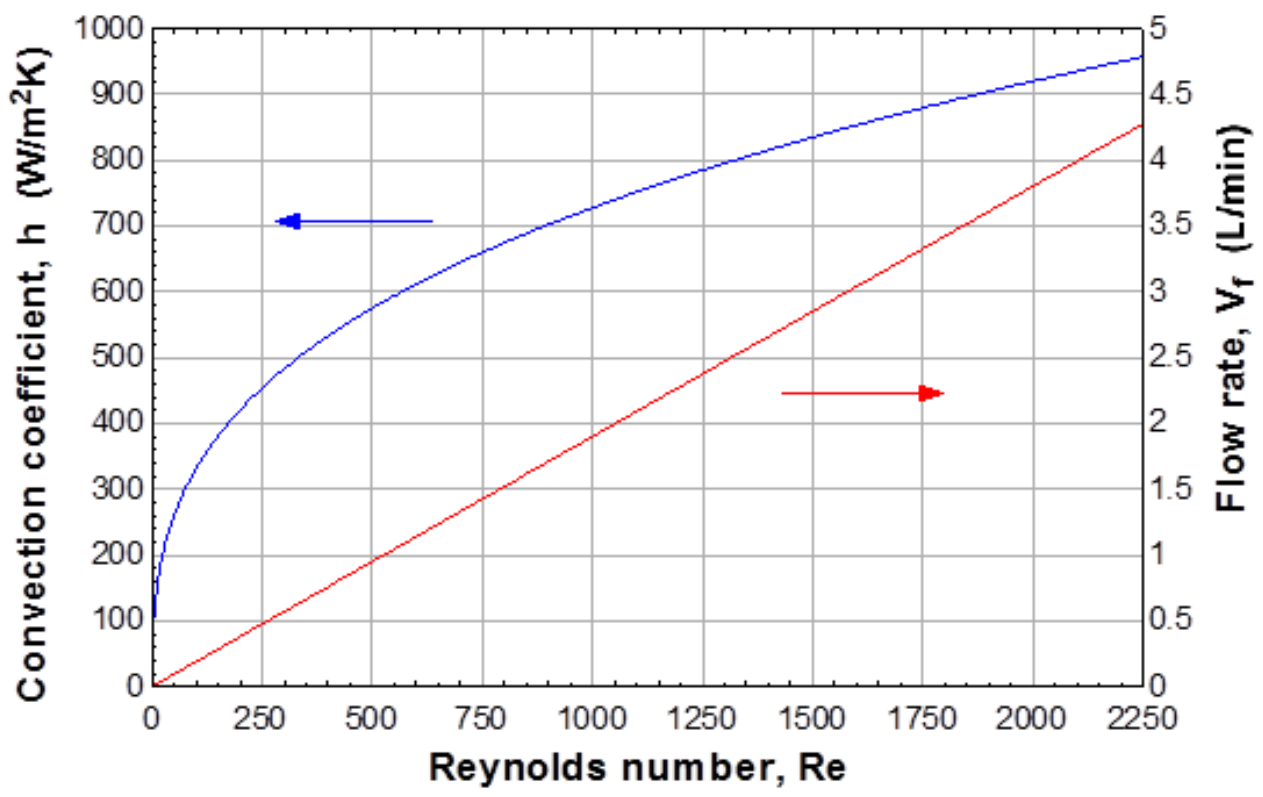

Figure 5 Predicted convection coefficient (Eq. (4)) and flow rate (Eq. (7)) vs. Reynolds number for the $32 \mathrm{~mm}$ tube. 


\subsection{Construction}

In order to reproduce the modelled heat transfer conditions, the flow loop shown in Figure 4f was built. A fluid reservoir was filled with a solution at $10 \%$ vol of water-ethylene glycol at ambient pressure. A pump recirculated the heat transfer fluid from the storage tank, through the flow loop and the sensor section. Rubber hoses were used to connect the main components of the setup. A plate heat exchanger coupled to a chiller was used to absorb the pump work and maintain a constant fluid temperature at the inlet to the test section. A filter was used to remove particles from the fluid. A by-pass line and a needle valve were used to regulate the flow through the main test section, while two needle valves adjusted the flow on the main test line. A flow damper absorbed the pressure ripple caused by the pump, stabilizing the flow. A flow meter and a thermocouple measured the fluid flow rate and temperature, respectively, at the inlet of the main test section.

The test section was designed with an inner diameter of $D_{h}=32 \mathrm{~mm}$, as stated in the previous paragraphs. A plastic inlet adapter received the flow from the rubber hose and conveyed it into a $2 \mathrm{~m}$ long acrylic straight pipe. At the end of the $2 \mathrm{~m}$ long pipe the sensor section was connected (Figure 6) and the sensor itself mounted. The sensor section was fabricated in POM, while the sensor head and casing were manufactured in aluminum, with a thermal conductivity of $210 \mathrm{~W} / \mathrm{mK}$, to maximize thermal conduction from the heater to the fluid. This guaranteed a Biot number varying from 0.0003 to 0.03 in the desired range of operation, which indicates that the temperature of the inner face of the sensor is very close to the temperature of the surface in contact with the liquid. At the end of the sensor section, a plastic collector received the flow and led it back to the storage tank. Before the interaction with the sensor, a straight pipe section of $\sim 2.5 \mathrm{~m}$ was provided for the development of the velocity profile. A gradually enlarging inlet section and a honeycomb flow straightener were used to decrease the theoretical entrance length. An $8.2 \times 7.3 \times 3.6 \mathrm{~mm}$ surface-mounted (SM) power resistor $R_{e l}=221 \Omega$ was used as a dissipating element in the sensor. The resistor was glued to the inner side of the sensor head with a thin layer of thermal epoxy $(k=7.2 \mathrm{~W} / \mathrm{m}-\mathrm{K})$ and connected to a power supply. A type-E thermocouple was located next to the resistor, mounted with the same epoxy to monitor the temperature of the dissipating surface.

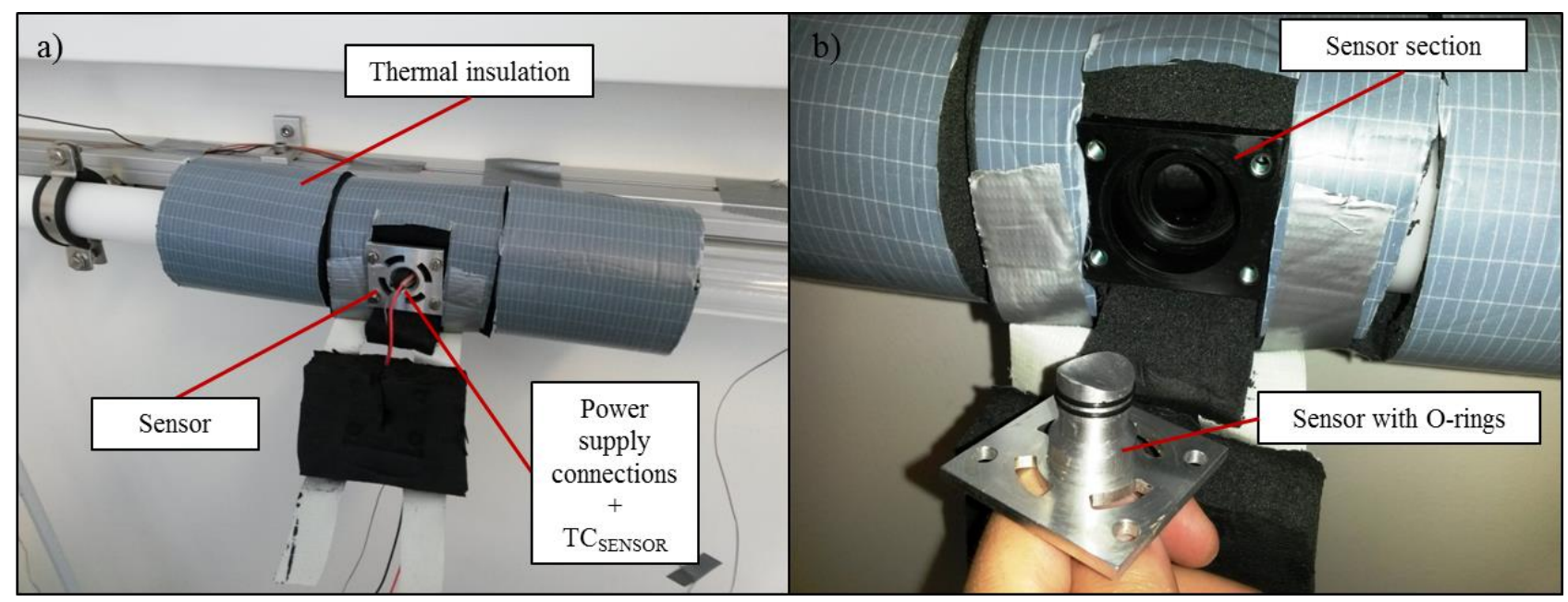

Figure 6 Pictures of the sensor section (a), and of the disassembled sensor (b). 
A data acquisition system was set up with National Instruments' equipment and interfaced to the laboratory computer. The quantities that were monitored through the DAQ are listed in Table 1.

Table 1 Summary of the DAQ system.

\begin{tabular}{lll}
\hline \multicolumn{1}{c}{ Quantity } & \multicolumn{1}{c}{ Instrument } & \multicolumn{1}{c}{ Acquisition } \\
\hline $\begin{array}{ll}\text { Flow rate through the test } \\
\text { section }\end{array}$ & $\begin{array}{l}\text { Turbine flow meter 1: } 0.05-0.5 \mathrm{~L} / \mathrm{min} \\
\text { Vortex flow meter 2: } 0.5-10 \mathrm{~L} / \mathrm{min}\end{array}$ & $\begin{array}{l}\text { NI 9203 - 4-20 mA input } \\
\text { with screw terminal }\end{array}$ \\
\hline Inlet temperature & Type-E thermocouple & $\begin{array}{l}\text { NI 9212 - } \pm 78 \mathrm{mV} \text { input } \\
\text { with screw terminal }\end{array}$ \\
\hline Sensor temperature & Type-E thermocouple & \\
\hline Ambient temperature & 2x Type-E thermocouples & Rigol DP832 \\
\hline Feed voltage to the sensor & Power supply (3 channels: $30-30-5 \mathrm{~V})$ &
\end{tabular}

\subsection{Experimental procedure}

An interface with the DAQ system was developed to acquire, display and record the measured quantities. In accordance with the chosen approach (2) (see Section 3), a PID control was implemented to regulate the power to the heating element. The PID control loop aimed at adjusting the voltage and the power across the dissipating element, so the temperature span between the sensor $\left(T_{\text {SENSOR }}\right)$ and the convective fluid $\left(T_{\text {INLET }}\right)$ could be regulated at the set point $\Delta T_{\text {SetPoint }}$.

In analogy with Eq. (2), the heat transfer coefficient was calculated by the sensor as:

$h=\frac{\dot{Q}}{A_{\text {SENSOR }} \cdot\left(T_{S E N S O R}-T_{I N L E T}\right)}$

Where $\dot{Q}$ is the power rejected from the dissipating surface to the heat transfer fluid. Such heat flux differs from the power dissipated in the heating element because of the heat leakages. Assuming otherwise would mean to overestimate $h$. The effect of the heat leakages was calibrated out of the calculations as illustrated in the following sections. 


\section{Results}

Tests were run for $\Delta T_{\text {SetPoint }}=5,10,15$, and $20^{\circ} \mathrm{C}$ to investigate which could provide the best accuracy, fastest response and highest resolution. The setup from Figure $4 \mathrm{f}$ was used to perform the experimental measurements and several flow rates were set through the flow loop for each different $\Delta T_{\text {SetPoint }}$. Once the system reached steady state, the measurement of the heat transfer coefficient was recorded and correlated to the flow rate and Reynolds number. A calibration procedure that could be reproduced on the downhole tool was sought to filter out the heat losses that affect accurate measurement of the convection coefficient.

\subsection{Uncalibrated measurements}

A first round of experiments was conducted and the heat transfer coefficient was calculated from Eq. (8), assuming $\dot{Q}$ equal to the total power dissipation of the resistive elements. The results are shown in Figure 7.

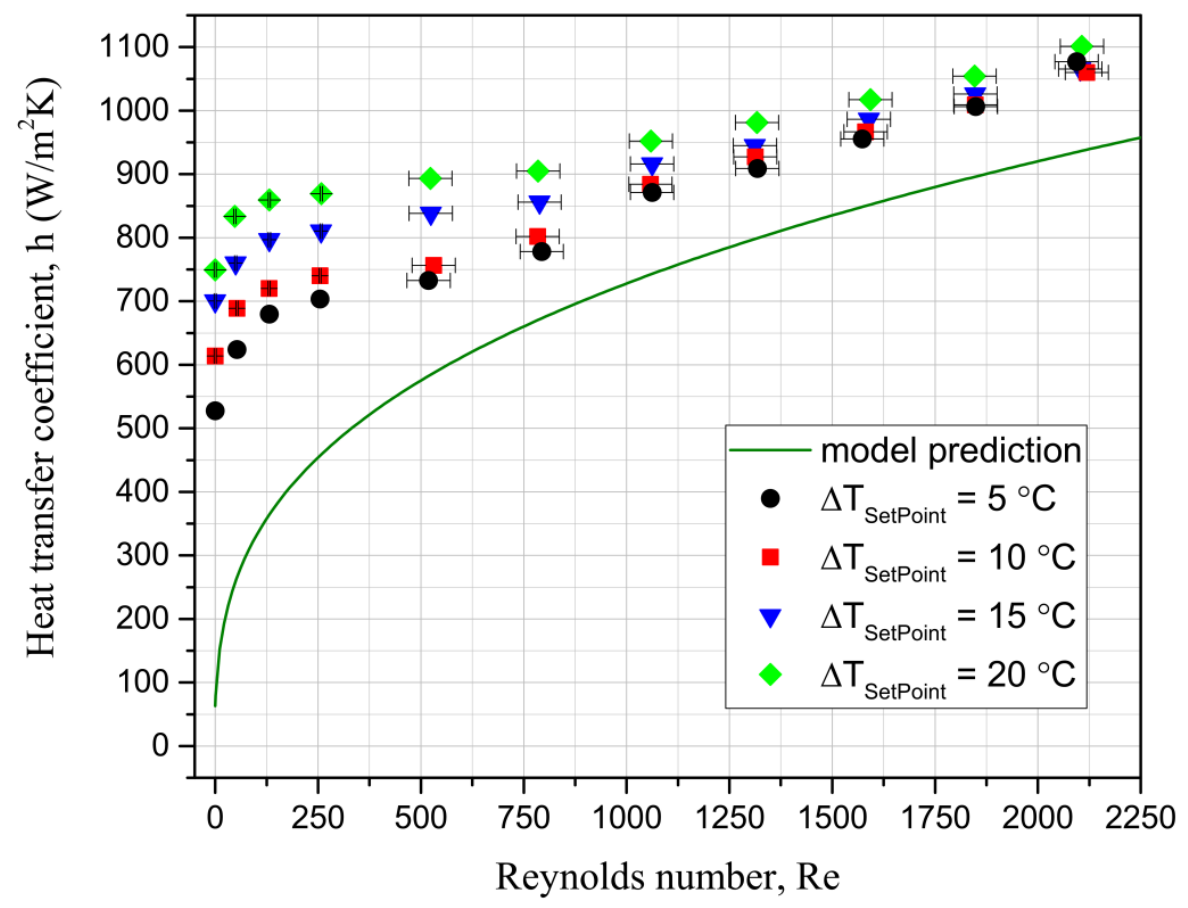

Figure 7 Heat transfer coefficient vs. fluid flow rate, without filtering of the heat losses. The model prediction is compared to the experimental data points for different $\Delta T_{\text {SetPoint }}$.

As expected, the heat transfer coefficient was overestimated compared to the model predictions. Part of the dissipated power in fact leaked to the ambient or to the fluid through alternative thermal paths. The mismatch with the model prediction appears higher for higher $\Delta T_{\text {SetPoint }}$ and lower $R e$ because of the higher and more impacting heat losses. In order to improve the accuracy of the sensor, the heat leakages needed to be compensated, as shown in the next sections. Furthermore, given the significantly higher impact of the thermal gradient across the sensor head and of the heat losses on the measurements at $\Delta T_{\text {SetPoint }}=15^{\circ} \mathrm{C}$ and $20{ }^{\circ} \mathrm{C}$, it was decided to focus the calibration of the system for $\Delta T_{\text {SetPoint }}=5^{\circ} \mathrm{C}$ and $10{ }^{\circ} \mathrm{C}$. 


\subsection{Compensation for heat losses}

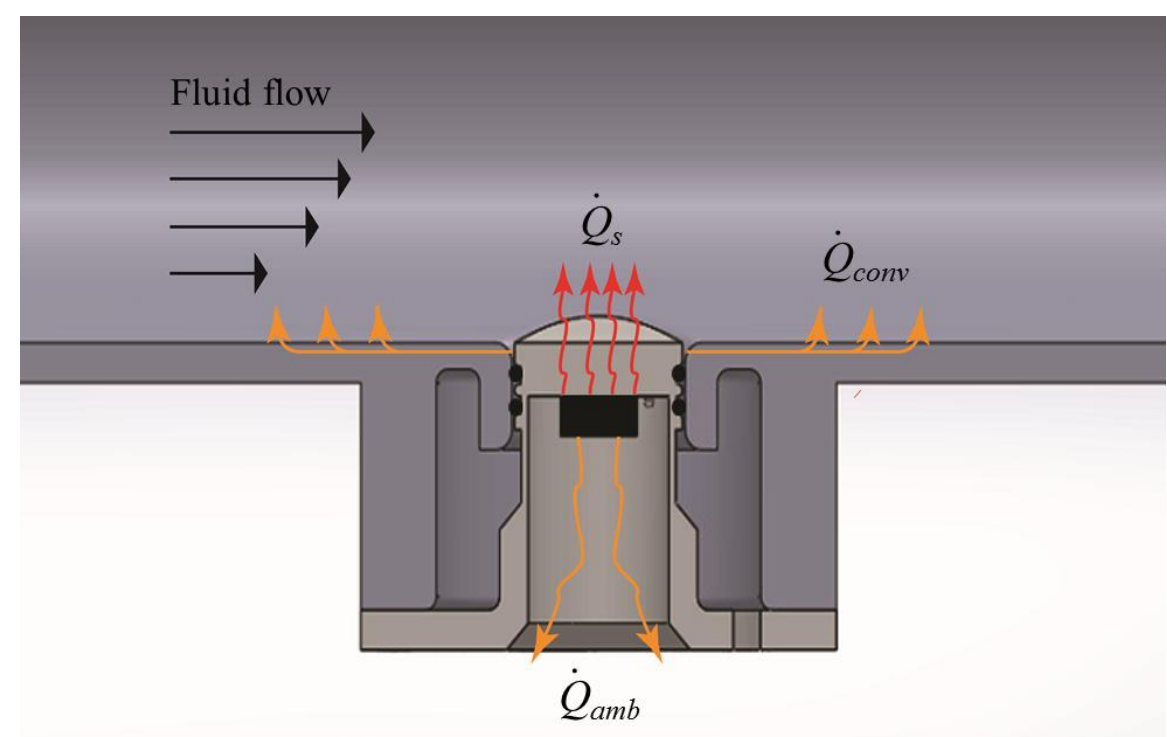

Figure 8 Schematic representation of the thermal interaction of the sensor with the setup and the surroundings.

The dissipated power in the sensor can be split in three different contributions, as shown in Figure 8: $\dot{Q}_{s}$ is the heat flux exchanged with the fluid through the surface of the sensor designed for the thermal interaction; $\dot{Q}_{a m b}$ is the part of the dissipated power which is lost to ambient through the insulation; and $\dot{Q}_{c o n v}$ is the heat flux leaked through the sensor casing, but still absorbed by the convective fluid. The impact of $\dot{Q}_{\text {conv }}$ on the measurements is higher at low flow rates, as discussed before, and still needs to be taken into account.

A series of tests were carried out to characterize the heat leakages to ambient through the thermal insulation. The test section was emptied of the heat transfer fluid and thermal insulation was applied on the dissipating surface of the sensor. In this way, the only heat sink for the power dissipated in the sensor was the ambient and the heat losses could be characterized. The ambient losses were therefore calculated by running the sensor and correlating the obtained temperature difference with ambient and the used feed power (Figure 9). The heat losses to ambient were characterized as $0.0253 \mathrm{~W} / \mathrm{K}$ times the temperature difference between the sensor and the ambient. 


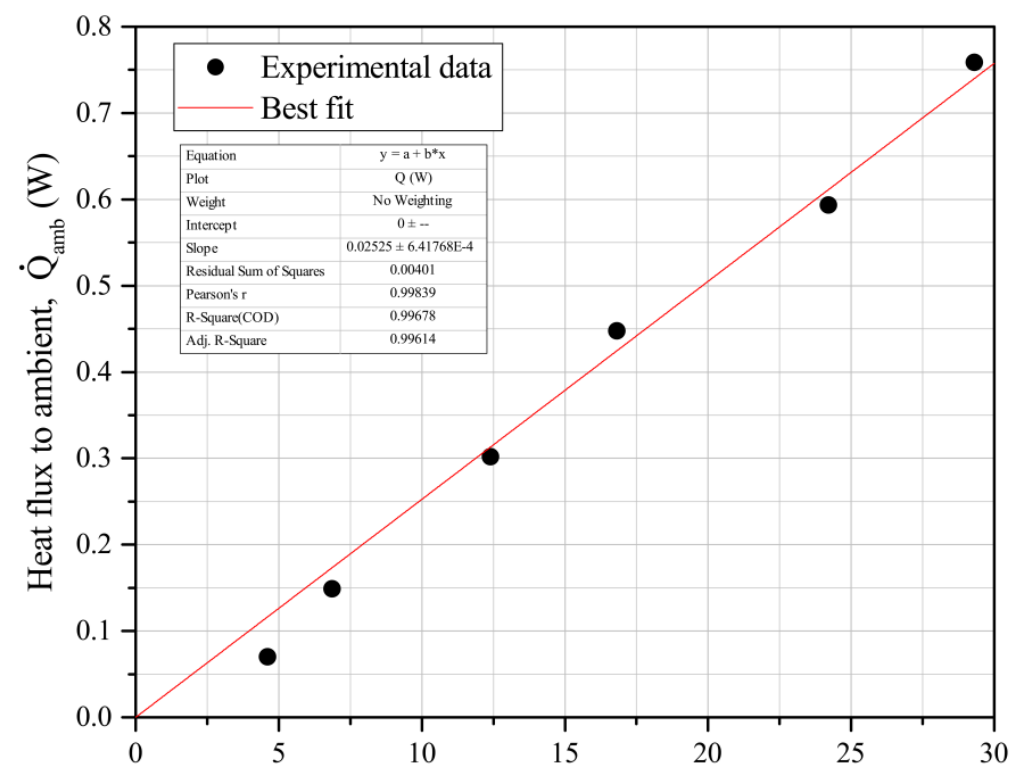

Temperature difference between sensor and ambient, $\mathrm{T}_{\text {SENSOR }}-\mathrm{T}_{\text {amb }}\left({ }^{\circ} \mathrm{C}\right)$

Figure 9 Heat losses from to ambient vs. temperature difference between sensor and ambient with no liquid present.

The heat losses from alternative thermal paths $\dot{Q}_{c o n v}$ were found to be relevant for Re below 250, as can be noticed by the mismatch between uncalibrated measurements and model predictions (Figure 8). Lower Reynolds numbers correspond, in fact, to higher thermal resistances between the sensor dissipating surface and the fluid, so part of the dissipated heat is more likely to leak to the fluid through alternative thermal paths in the surrounding components. In this range of low Reynolds numbers the losses $\dot{Q}_{c o n v}$ were modelled as proportional to a natural convection heat flux [34]. A proportionality coefficient $k$ was used for this purpose and calculated by comparing the uncalibrated measurements obtained for tests at $\Delta T_{\text {SetPoint }}=5{ }^{\circ} \mathrm{C}$ and $10{ }^{\circ} \mathrm{C}$. The convection coefficient values should in fact result the same in absence of losses and assuming that the influence of the different $\Delta T_{\text {SetPoint }}$ on the film properties is negligible.

The energy balance equations that were used in the calibration of the sensor and for the final expression of the heat transfer coefficient are reported below.

$$
\begin{aligned}
& \left.h\right|_{\Delta T_{\text {SetPoint }}=5{ }^{\circ} \mathrm{C}}=\left.h\right|_{\Delta T_{\text {SetPoint }}=10^{\circ} \mathrm{C}} \\
& \frac{\dot{Q}_{\text {Conv }}}{A_{\text {SENSOR }} \cdot\left(T_{\text {SENSOR }}-T_{\text {INLET }}\right)}=p\left(T_{\text {SENSOR }}-T_{I N L E T}\right)^{0.32} \\
& \dot{Q}_{s}=\dot{Q}_{\text {PowerSupply }}-\dot{Q}_{a m b}-\dot{Q}_{\text {conv }} \cdot(R e<250) \\
& h=\frac{\frac{V_{P S}^{2}}{R_{e l}}-0.0253 \cdot\left(T_{\text {SENSOR }}-T_{I N L E T}\right)-\dot{Q}_{\text {conv }} \cdot(R e<250)}{A_{\text {SENSOR }} \cdot\left(T_{\text {SENSOR }}-T_{\text {INLET }}\right)}
\end{aligned}
$$


Where $V_{P S}$ is the voltage across the heating element and $p$ is the proportionality coefficient. The comparison between the uncalibrated measurements led to values of $p$ of $208,156,97$, and $88 \mathrm{~W} / \mathrm{m}^{2} \mathrm{~K}^{1.32}$ for Reynolds numbers of $0,53,131$, and 232 , respectively. The calculated coefficients were used for the final calibration of the sensor. The results obtained with the calibrated expression of the heat transfer coefficient from Eq. (12) are reported in Figure 10 and compared with the model predictions.

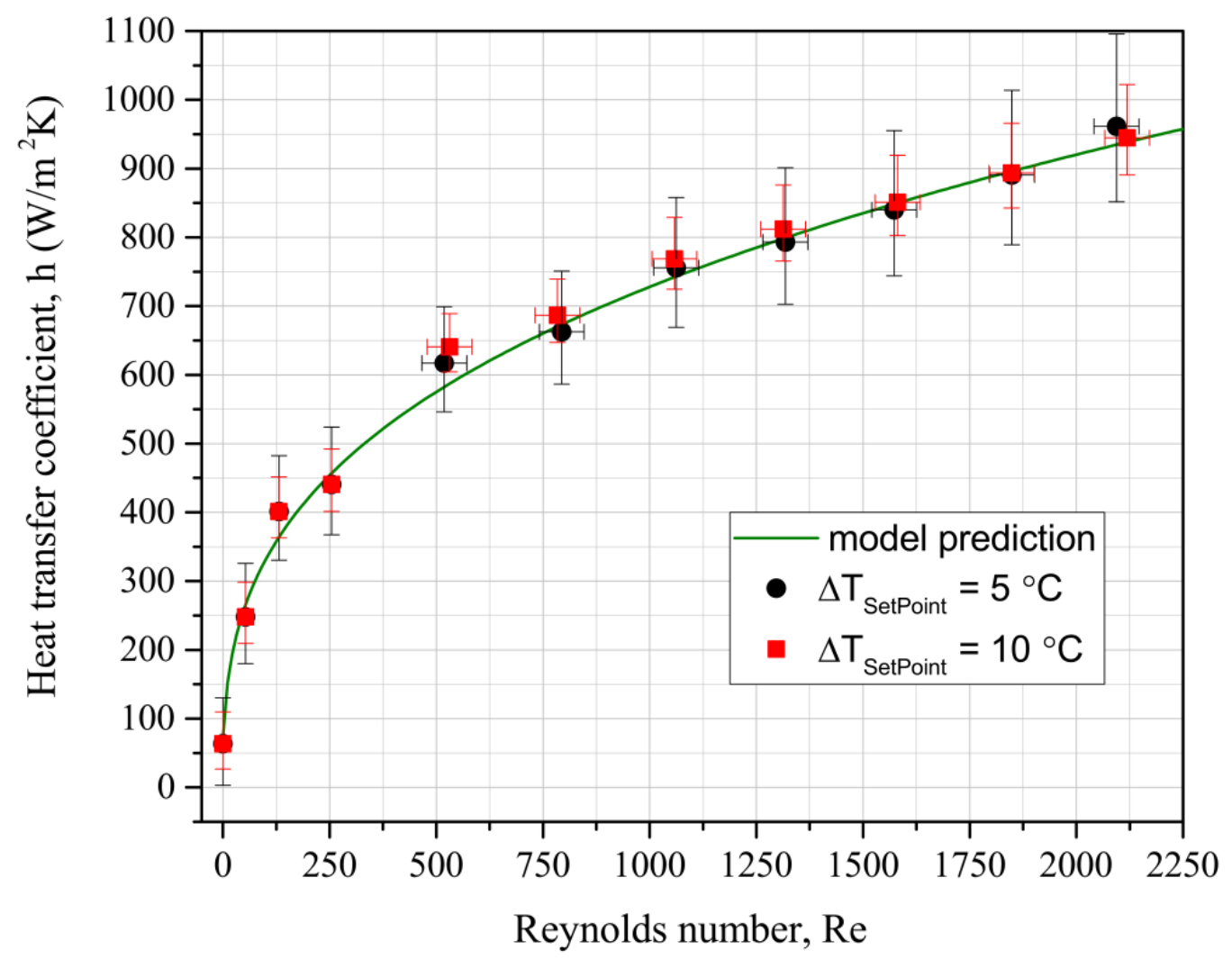

Figure 10 Heat transfer coefficient vs. fluid flow rate, calibrated for contribution of heat losses. The model prediction is compared to the experimental data points for different $\Delta T_{\text {SetPoint }}$.

Accounting for $\dot{Q}_{a m b}$ and $\dot{Q}_{\text {conv }}$ allowed filtering out the influence of the heat leakages, and more accurate measurements were obtained. The experimental results finally reproduced the model predictions very well, with an average and maximum errors of $\sim 3 \%$ and $\sim 10 \%$, respectively, for both the cases at $\Delta T_{\text {SetPoint }}=5{ }^{\circ} \mathrm{C}$ and $10{ }^{\circ} \mathrm{C}$. A summary of the experimental results can be found in the next sections. 


\subsection{Resolution and response time}
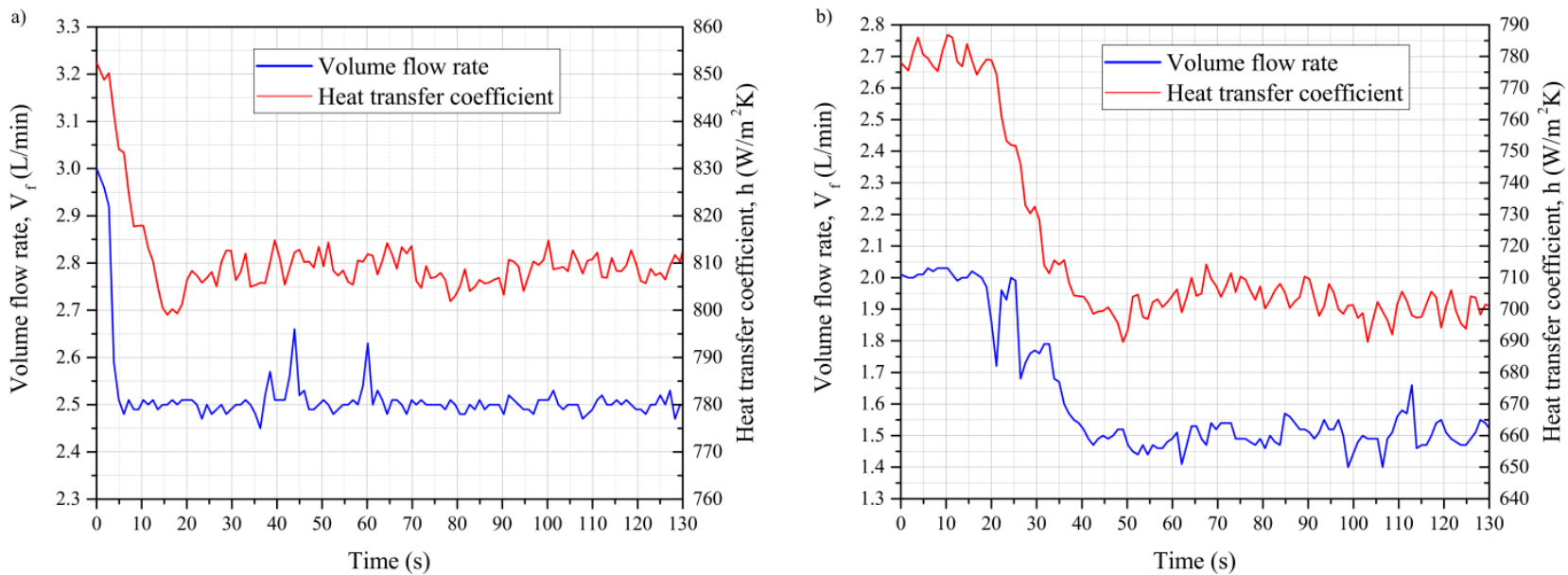

Figure 11 Representation of two system transients due to a change in the flow rate of $17 \%$ (a) and $25 \%$ (b). The change in flow rate corresponded to a change in the fluid speed of $\sim 1 \mathrm{~cm} / \mathrm{s}$ in both cases. Operations at a $\Delta T_{\text {SetPoint }}=10{ }^{\circ} \mathrm{C}$. A first estimation of the response time was done around 11 seconds for both cases.

Table 2 and Table 3 summarize the final results for the sensor calibration over the measurement range at $\Delta T_{\text {SetPoint }}=5^{\circ} \mathrm{C}$ and $10^{\circ} \mathrm{C}$, respectively. The average resolution characterizing the measurement is expressed for the two cases in millivolts per measured $\mathrm{W} / \mathrm{m}^{2} \mathrm{~K}$. A higher resolution was found for the approach at a $\Delta T_{\text {SetPoint }}=10{ }^{\circ} \mathrm{C}$, compared to the case at $\Delta T_{\text {SetPoint }}=5{ }^{\circ} \mathrm{C}$, due to the higher voltage increment required to maintain the higher temperature difference.

It could be observed that higher set point temperature differences provided better resolution of the measurements. The choice of the resistance of the dissipating element also affects the resolution of the voltage readings, whereas a higher resistance gives a better resolution. Nevertheless, the choice of the dissipating element must still be compatible with the available downhole power source. A tradeoff needs to be reached and a $\Delta T_{\text {SetPoint }}=10{ }^{\circ} \mathrm{C}$ proved to be the best compromise for this study in terms of accuracy and resolution.

The response time of the sensor to a change of flow rate was also monitored for the case with $\Delta T_{\text {SetPoint }}=10^{\circ} \mathrm{C}$. A response time of $\sim 11 \mathrm{~s}$ was estimated for a decrease of the fluid speed of $25 \%$, which can be considered a sudden and significant velocity change for a well fluid in a borehole. Although the observed response time in Figure 11 is promising, further improvements are possible through different PID settings and reduced thermal mass of the sensor.

\subsection{Measurements and uncertainties}

The uncertainty of the heat transfer coefficient was calculated from the uncertainty of each measured quantity described in Eq. (12). The effect of the thermal gradient across the sensor was also analyzed as a source of uncertainty. 
The E-type thermocouples were calibrated with a thermal bath Julabo FP50-HL to an uncertainty of $\pm 0.4{ }^{\circ} \mathrm{C}$. The voltage across the resistor was read with a Rigol DP832 with an uncertainty of $0.05 \%$ of the read value plus an offset of $10 \mathrm{mV}$. The resistance of $221 \Omega$ was measured with a multimeter Fluke 117 and an uncertainty of $\pm 0.1 \Omega$. The total uncertainty of the heat transfer coefficient was then calculated from Eq. (12) according to the following expression:

$\delta h=\sqrt{\left(\frac{\partial h}{\partial V_{P S}} \delta V_{P S}\right)^{2}+\left(\frac{\partial h}{\partial R_{e l}} \delta R_{e l}\right)^{2}+\left(\frac{\partial h}{\partial \Delta T_{a m b}} \delta \Delta T_{a m b}\right)^{2}+\left(\frac{\partial h}{\partial \Delta T_{S E N S O R}} \delta \Delta T_{\text {SENSOR }}\right)^{2}}$

Where $\Delta T_{\text {amb }}=T_{\text {SENSOR }}-T_{\text {amb }}$ and $\Delta T_{\text {SENSOR }}=T_{\text {SENSOR }}-T_{\text {INLET }}$. The uncertainty of the temperature differences were calculated as follows:

$\delta \Delta T=\sqrt{\delta T_{1}^{2}+\delta T_{2}^{2}}$

Table 2 Summary of the experimental results for the sensor calibration from the tests at $\Delta T_{\text {SetPoint }}=5^{\circ} \mathrm{C}$.

\begin{tabular}{|c|c|c|c|c|c|c|}
\hline $\begin{array}{c}h_{\text {model }} \\
\left(W / m^{2} K\right)\end{array}$ & $\begin{array}{l}h_{\text {calibrated }} \\
\left(W / m^{2} K\right)\end{array}$ & $\begin{array}{c}\text { Error } \\
(\%)\end{array}$ & $\begin{array}{c}\text { Voltage reading } \\
(V)\end{array}$ & $\begin{array}{c}\delta h \\
\left(W / m^{2} K\right)\end{array}$ & $\begin{array}{l}\delta h_{\text {per }} \\
(\%)\end{array}$ & $\begin{array}{l}\delta h_{\text {gradient }} \\
\left(W / m^{2} K\right)\end{array}$ \\
\hline 63.2 & 63.6 & 0.6 & 10.9 & \pm 60.6 & 95.4 & $\pm_{60.6}^{66.8}$ \\
\hline 265.1 & 248.2 & 6.4 & 12.4 & \pm 68.3 & 27.5 & $\mathbf{\pm}_{68.3}^{77.6}$ \\
\hline 364.2 & 401.4 & 10.2 & 12.7 & \pm 70.9 & 17.7 & $\mathbf{1}_{70.9}^{80.9}$ \\
\hline 427.4 & 440.6 & 3.1 & 12.8 & \pm 73.1 & 16.6 & $\mathbf{1}_{73.1}^{83.6}$ \\
\hline 582.5 & 617.1 & 5.9 & 13.1 & \pm 71.0 & 11.5 & $\pm_{71.0}^{81.8}$ \\
\hline 673.1 & 662.5 & 1.6 & 13.5 & \pm 76.1 & 11.5 & $\mathbf{1}_{76.1}^{88.4}$ \\
\hline 742.9 & 755.8 & 1.7 & 14.3 & \pm 86.5 & 11.4 & $\pm_{86.5}^{102.1}$ \\
\hline 799.3 & 793.2 & 0.8 & 14.7 & \pm 90.7 & 11.4 & $\pm_{90.7}^{108.0}$ \\
\hline 848.6 & 839.9 & 1.0 & 15.0 & \pm 95.9 & 11.4 & $\pm_{95.9}^{115.1}$ \\
\hline 896.1 & 890.9 & 0.6 & 15.4 & \pm 101.7 & 11.4 & $\pm_{101.7}^{122.9}$ \\
\hline 934.7 & 961.3 & 2.8 & 16.0 & \pm 109.6 & 11.4 & $\pm_{109.6}^{134.4}$ \\
\hline \multicolumn{2}{|c|}{$\begin{array}{c}\text { Average resolution } \\
\left(\mathrm{mV} \text { per } \mathrm{W} / \mathrm{m}^{2} \mathrm{~K}\right)\end{array}$} & & 6.6 & & & \\
\hline
\end{tabular}

Table 3 Summary of the experimental results for the sensor calibration from the tests at $\Delta T_{\text {SetPoint }}=10^{\circ} \mathrm{C}$.

\begin{tabular}{ccccccc}
\hline $\begin{array}{c}h_{\text {model }} \\
\left(W / m^{2} K\right)\end{array}$ & $\begin{array}{c}h_{\text {calibrated }} \\
\left(W / m^{2} K\right)\end{array}$ & $\begin{array}{c}\text { Error } \\
(\%)\end{array}$ & $\begin{array}{c}\text { Voltage reading } \\
(V)\end{array}$ & $\begin{array}{c}\delta h \\
\left(W / m^{2} K\right)\end{array}$ & $\begin{array}{c}\delta h_{\text {per }} \\
(\%)\end{array}$ & $\begin{array}{c}\delta h_{\text {gradient }} \\
\left(W / m^{2} K\right)\end{array}$ \\
\hline 63.2 & 63.6 & 0.6 & 17.2 & 36.7 & 57.6 & $\pm_{36.7}^{46.2}$ \\
\hline 265.2 & 248.2 & 6.4 & 18.1 & 38.9 & 15.7 & $\pm_{38.9}^{50.3}$ \\
\hline 363.5 & 401.4 & 10.4 & 18.5 & 38.5 & 9.6 & $\pm_{38.5}^{50.0}$ \\
\hline
\end{tabular}




\begin{tabular}{ccccccc}
\hline 457.0 & 440.6 & 3.6 & 18.8 & 39.2 & 8.9 & $\pm_{39.2}^{51.4}$ \\
\hline 587.2 & 640.8 & 9.1 & 19.0 & 36.6 & 5.8 & $\pm_{36.6}^{48.1}$ \\
\hline 670.2 & 686.6 & 2.4 & 19.7 & 39.4 & 5.7 & $\pm_{39.4}^{52.8}$ \\
\hline 741.9 & 768.6 & 3.6 & 20.5 & 44.0 & 5.7 & $\pm_{44.0}^{60.2}$ \\
\hline 798.3 & 811.9 & 1.7 & 20.9 & 46.4 & 5.7 & $\pm_{46.4}^{64.2}$ \\
\hline 850.1 & 851.2 & 0.1 & 21.4 & 48.6 & 5.7 & $\pm_{48.6}^{68.1}$ \\
\hline 896.0 & 893.7 & 0.3 & 21.9 & 51.0 & 5.7 & $\pm_{51.0}^{72.4}$ \\
\hline 938.5 & 944.7 & 0.7 & 22.5 & 53.9 & 5.7 & $\pm_{53.9}^{77.7}$ \\
\hline $\begin{array}{c}\text { Average resolution } \\
\left(\mathrm{mV} \text { per } \mathrm{W/m}{ }^{2} \mathrm{~K}\right)\end{array}$ & & 8.7 & & & \\
\hline
\end{tabular}

Table 2 and 3 report the heat transfer coefficient measurements for the cases with $\Delta T_{\text {SetPoint }}=5{ }^{\circ} \mathrm{C}$ and $\Delta T_{\text {SetPoint }}=10^{\circ} \mathrm{C}$, together with the estimated uncertainties $\delta h$. Lower heat transfer coefficients are affected by higher uncertainties, which range from $95 \%$ to $11 \%$ of the measured value for the case $\Delta T_{\text {SetPoint }}=5{ }^{\circ} \mathrm{C}$; and from $58 \%$ to $6 \%$ of the measured value for the case $\Delta T_{\text {SetPoint }}=10{ }^{\circ} \mathrm{C}$. A higher $\Delta T_{\text {SetPoint }}$ provides a better accuracy to the measurement, although contributes to a higher temperature gradient across the sensor and larger heat leakages,

It was found that the uncertainty of the temperature probes has the largest impact on the sensor accuracy and that a more precise calibration or choosing a more accurate temperature probe such as a thermistor could significantly improve the measurements of $h$. It was estimated that reducing the temperature uncertainty from $\pm 0.4{ }^{\circ} \mathrm{C}$ to $\pm 0.1{ }^{\circ} \mathrm{C}$ would reduce $\delta h_{p e r}$ from $95 \%$ to $24 \%$ and from $11 \%$ to $3 \%$ for $\Delta T_{\text {SetPoint }}=5{ }^{\circ} \mathrm{C}$; from $58 \%$ to $15 \%$ and from $6 \%$ to $1 \%$ for $\Delta T_{\text {SetPoint }}=10{ }^{\circ} \mathrm{C}$. However, thermocouples have a faster time response and would allow the sensor to detect changes in well conditions more quickly. The final choice of the temperature probe will depend on the importance of accurately measuring low convection coefficients versus fast response.

The temperature gradient across the sensor head could be considered an additional source of uncertainty. When neglected the temperature difference $T_{I N L E T}-T_{S E N S O R}$ is overestimated, and the measured heat transfer coefficient underestimated. The effect of the temperature gradient has a higher impact on the accuracy at high heat transfer coefficients because of the higher dissipated heat fluxes. However, this uncertainty source could be filtered off by iteratively calibrating the effect of the temperature gradient out of Eq. (12) and calculating the new heat flux across the sensor head $\dot{Q}_{s}$. 


\subsection{Intended downhole operation}

The integration concept of the sensor in a downhole tool was presented in Section 3 and illustrated in Figure 4. The calibration of the sensor in a downhole tool could follow the same procedure as the one reported in section 5.2, given the analogy between the analyzed environments. Figure 12 illustrates the analogy between the scenario studied in the lab and the intended operation in a downhole environment.

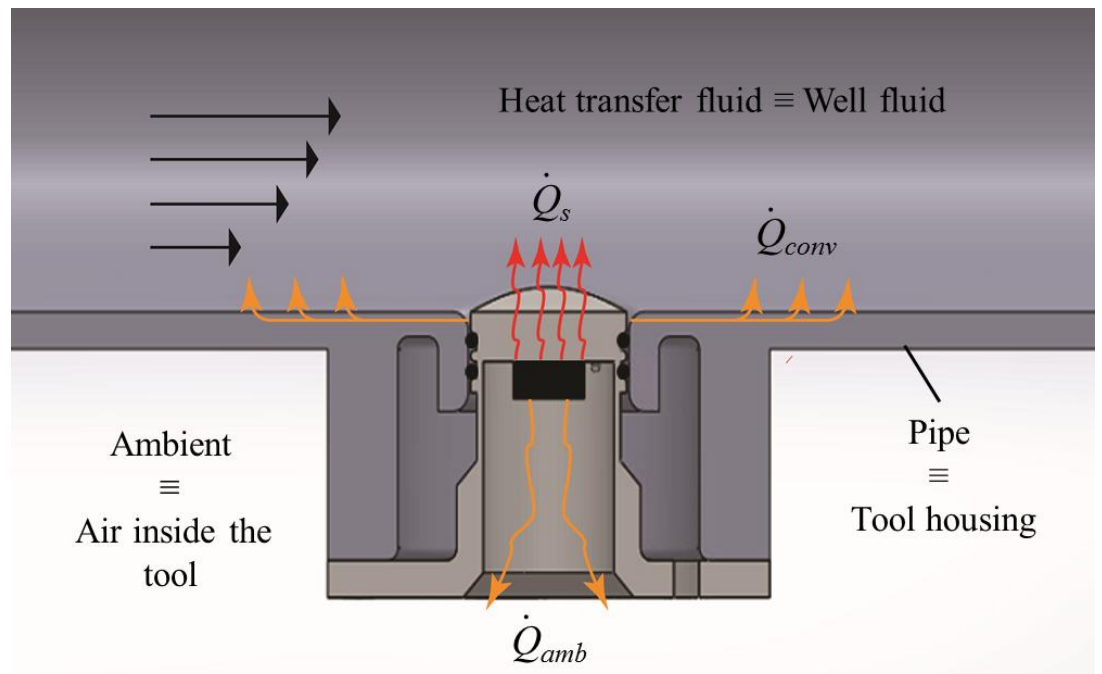

Figure 12 Analogy between the studied lab case and the intended downhole operation.

In the downhole scenario, the heat losses to ambient correspond to the losses towards the environment inside the tool housing. Using a temperature probe that monitors the air temperature inside the tool, the same procedure could be followed to account for these leakages, while the outer surface of the tool housing is thermally insulated. The temperature sensor in the tool could be eliminated by calculating the tool temperature for a given convection coefficient and applying an iterative process to improve accuracy. The convective leakages to the heat transfer fluid correspond, instead, to the convective losses through the tool housing to the well fluid. In an analogue way to the one presented in Section 5.2, a convective term could be included in the calibrated expression of $h$ to filter these losses out. Introducing a thermally insulating layer between the sensor and the tool housing would also help to reduce the heat leakages and increase accuracy. Reducing the wall thickness or choosing a material with a higher thermal conductivity would reduce measurement errors due to the temperature gradient in the sensor wall.

\section{Conclusions}

This article presented the design and proof-of-concept of a sensor for measuring the heat transfer coefficient between a downhole tool and the downhole environment. The design process aimed at developing a sensor that relies on robust components available at high temperatures, has a low-complexity, can be easily integrated in a downhole tool, and can operate in harsh environments. The sensor was manufactured and tested in the lab. 
An experimental flow loop was designed to reproduce known convective heat transfer conditions and compare the experimental measurements to known correlations from the literature. A procedure for calibrating the sensor that is also applicable to operations in a downhole tool was developed and consisted of: (i) the implementation of a PID control that could regulate the temperature span between the dissipating surface of the sensor and the convective fluid, (ii) the estimation of the heat transfer losses, and (iii) the comparison between measurements at different $\Delta T_{\text {SetPoint }}$.

Good agreement between the model predictions and the calibrated measurements at $\Delta T_{\text {SetPoint }}$ of $5{ }^{\circ} \mathrm{C}$ and $10{ }^{\circ} \mathrm{C}$ was obtained, with an average error of $\sim 3 \%$ and maximum error of $\sim 10 \%$. A higher resolution equal to $8.7 \mathrm{mV}$ per W/m $/ \mathrm{m}^{2} \mathrm{~K}$ was found for $\Delta T_{\text {SetPoint }}=10^{\circ} \mathrm{C}$, compared to $6.6 \mathrm{mV}$ per W/m $/ \mathrm{m}^{2} \mathrm{~K}$ for $\Delta T_{\text {SetrPoint }}=5{ }^{\circ} \mathrm{C}$. A promising response time of $\sim 11 \mathrm{~s}$ for a $25 \%$ change in fluid velocity was also observed.

The uncertainty analysis showed that the accuracy of the heat transfer measurements strongly depends on the precision of the temperature probes. With a $\pm 0.4{ }^{\circ} \mathrm{C}$ temperature uncertainty, the uncertainty over the measured heat transfer coefficient could be as high as $95 \%\left( \pm 60.6 \mathrm{~W} / \mathrm{m}^{2} \mathrm{~K}\right)$ of the measured value for $\Delta T_{\text {SetPoint }}=5{ }^{\circ} \mathrm{C}$, and up to $57 \%\left( \pm 36.7 \mathrm{~W} / \mathrm{m}^{2} \mathrm{~K}\right)$ for $\Delta T_{\text {SetPoint }}=10^{\circ} \mathrm{C}$. However, the calculated accuracy can be considered acceptable for this type of application, as accurate measurement of low convection coefficients may not be critical. Significant improvements could be obtained by using more accurate temperature probes. The response time and the resolution of the sensor are expected to change not only with its thermal mass, but also with the thermal mass and thermal conductivity of the surroundings. The response time and the resolution of the sensor could differ in the case of integration in a downhole tool and should be opportunely analyzed. The implementation of a thermally insulating system around the sensor would be more complex in a downhole environment, given the harsher conditions. However, the reduced mass of the sensor (no plate and screws would be required), and the smaller area of the casing in contact with other components, should benefit its accuracy. Given the small dimensions and the modular configuration, more than one sensor could be installed in one tool string. Several sensors, measuring the heat transfer coefficient locally, would help to characterize the heat transfer profile along the whole tool string.

\section{Acknowledgements}

The authors would like to show their gratitude to the Danish Ministry of Technology and Innovation (contract 1355-00051B) and to Welltec A/S for partially funding this work.

\section{References}

[1] Shadravan A. , Amani, M. HPHT 101: What Every Engineer or Geoscientist Should Know about High Pressure High Temperature Wells, SPE Kuwait International Petroleum Conference and Exhibition, Kuwait (2012). http://dx.doi.org/10.2118/163376-ms

[2] Werner M.R., Fahrner W.R.. Review on Materials, Microsensors, Systems and Devices for High-Temperature and Harsh-Environment Applications, IEEE Transactions on Industrial Electronics 48, no. 2: 249-257 (2001). http://dx.doi:10.1109/41.915402 

Downhole Electronics in Harsh Thermal Environments, Appl Therm Eng, 118: 593-599 (2017). https://doi:10.1016/j.applthermaleng.2017.01.118

[4] Jakaboski J. C. Innovative Thermal Management of Electronics in Oil Well Logging, M.Sc. thesis, Georgia Institute of Technology USA (2004).

[5] Ma Y. , Shang B. , Hu R. , Luo X. Thermal Management of Downhole Electronics Cooling in Oil \& Gas Well Logging at High Temperature, 17th International Conference on Electronic Packaging Technology (ICEPT), (2016). http://doi:10.1109/icept.2016.7583211

[6] Bennett G. A. Active Cooling for Downhole Instrumentation: Preliminary Analysis and System Selection, Los Alamos National Laboratory, Mexico (1988). http://dx.doi.org/10.2172/5360643

[7] Flores A. G. Active Cooling for Electronics in a Wireline Oil-Exploration Tool, Ph.D. Thesis, M.I.T., USA (1996).

[8] Sinha A. , Joshi Y. K. Downhole Electronics Cooling Using a Thermoelectric Device and Heat Exchanger Arrangement, J Electron Packag, 133(4): 041005-1 - 041005-12 (2011). http://dx.doi.org/10.1115/1.4005290

[9] Pennewitz E. , Kruspeb T. , Jungb S. , Schillinga M. Evaluation of Sorbents at Elevated Temperatures for Downhole Application, Chem Eng Trans, 29: 1543-1548 (2012). http://dx.doi.org/10.3303/CET1229258

[10] Soprani S. , Engelbrecht K. , Nørgaard A. J. Active Cooling and Thermal Management of a Downhole Tool Electronics Section, Proceedings of the 24th IIR International Congress of Refrigeration, IIF-IIR, Yokohama, Japan (2015).

[11] Soprani S. , Haertel J. H. K. , Lazarov B. S. , Sigmund O. , Engelbrecht K. A design approach for integrating thermoelectric devices using topology optimization, Appl Energ, 176: 49-64 (2016).

https://doi.org/10.1016/j.apenergy.2016.05.024

[12] Verma S., Elias Q. Thermal Management of Electronics Used in Downhole Tools, SPE Annual Technical Conference and Exhibition (2012). http://dx.doi.org/10.2118/159737-ms

[13] Santoyo-Gutierrez E. R. Transient Numerical Simulation of Heat Transfer Processes During Drilling of Geothermal Wells, Ph.D. Thesis, University of Salford, UK (1997).

[14] Li M. , Liu G. , Li J. , Zhang T. , He M. Thermal Performance Analysis of Drilling Horizontal Wells in High Temperature Formations, Appl Therm Eng, 78: 217-27 (2015). http://dx.doi.org/10.1016/j.applthermaleng.2014.12.055

[15] Li G, Yang M, Meng Y, Wen Z, Wang Y, Yuan Z. Transient Heat Transfer Models of Wellbore and Formation Systems During the Drilling Process Under Well Kick Conditions in the BottomHole, Appl Therm Eng, 93: 339-47 (2016). http://dx.doi.org/10.1016/j.applthermaleng.2015.09.110

[16] Hasan A.R., Kabir C.S. Wellbore Heat-transfer Modeling and Applications, J Petrol Sci Eng, 86-87: 127-136 (2012). http://dx.doi.org/10.1016/j.petrol.2012.03.021 
[17] Keller H.H., Couch E.J., Berry P.M. Temperature Distribution in Circulating Mud Columns. Soc Petro Eng J, 13(1): 23-30 (1973). http://dx.doi.org/10.2118/3605-pa

[18] Beirute R.M. A Circulating and Shut-in Well-Temperature-Profile Simulator. J Petrol Sci Eng, 43(9): 1140-1146 (1991). http://dx.doi.org/10.2118/17591-pa

[19] Zhou F. Research on Heat Transfer in Geothermal Wellbore and Surroundings, Technischen Universität Berlin, M.Sc. Thesis (2013).

[20] Yang M. , Zhao X. , Meng Y. , Li G. , Zhang L. , Xu H. , Daqian T. Determination of transient temperature distribution inside a wellbore considering drill string assembly and casing program, Appl Therm Eng, 118:299-314 (2017). http://dx.doi.org/10.1016/j.applthermaleng.2017.02.070

[21] Carotenuto A. , Massarotti N. , Mauro A. A new methodology for numerical simulation of geothermal down-hole heat exchangers. Appl Therm Eng, 48:225-36 (2012). http://dx.doi.org/10.1016/j.applthermaleng.2012.04.021

[22] Diller T.E. Heat flux, in: J.G. Webster (Ed.), The Measurement Instrumentation and Sensors Handbook, CRC Press 1999, 34.1-34.15 (Chapter 34).

[23] Ortolano D. J., Hines F. F. A simplified approach to heat flow measurement. Adv Instr Vol. 38 Part II, Research Triangle Park: ISA, 1449-1456 (1983).

[24] Gardon R. , An instrument for the direct measurement of intense thermal radiation, Rev Sci Instrum, 24: 366-370 (1953).

[25] Liebert C. H. Miniature convection cooled plug-type heat flux gages, Proc 40th Int Instrum Symp, Research Triangle Park, NC: ISA 1994, 289-302.

[26] Mocikat H. , Herwig H. Heat Transfer Measurements with Surface Mounted Foil-Sensors in an Active Mode: A Comprehensive Review and a New Design, Sensors, 9(4):3011-32 (2009). http://dx.doi.org/10.3390/s90403011

[27] Pullins C.A., Diller T.E. In situ High Temperature Heat Flux Sensor Calibration, Int J Heat Mass Tran, 53(17-18): 3429-38 (2010). http://dx.doi.org/10.1016/j.ijheatmasstransfer.2010.03.042

[28] Dour G. , Dargusch M. , Davidson C. , Nef A. Development of a non-intrusive heat transfer coefficient gauge and its application to high pressure die casting, J Mater Process Tech, 169(2): 223-33 (2005). http://dx.doi.org/10.1016/j.jmatprotec.2005.03.026

[29] Nagaiah N.R., Kapat J.S., An L., Chow L. Novel polymer derived ceramic-high temperature heat flux sensor for gas turbine environment, $J$ Phys Conf Ser, 34:458-63 (2006). http://dx.doi.org/10.1088/1742-6596/34/1/075

[30] O’Dowd D. , Zhang Q. , Ligrani P. , He L. , Friedrichs S. Comparison of Heat Transfer Measurement Techniques on a Transonic Turbine Blade Tip. Heat Transfer, Parts A and B, Vol 3 (2009). http://dx.doi.org/10.1115/gt2009-59376 
[31] Kakaç S. , R.K. Shah , W. Aung. Handbook of Single-Phase Convective Heat Transfer. Wiley 1987.

[32] EES 2016, Engineering Equation Solver, F-Chart Software.

[33] Kakaç S. , Y. Yener. Convective Heat Transfer: Second Edition, CRC Press, 1995.

[34] Kitamura K. , Kimura F. Heat Transfer and Fluid Flow of Natural Convection Adjacent to Upward-Facing Horizontal Plates, Int $J$ Heat Mass Tran, 38(17): 3149-3159 (1995). http://dx.doi.org/10.1016/0017-9310(95)00066-i 